\title{
Convergence to Common Fixed Point for Two Asymptotically Quasi-nonexpansive Mappings in the Intermediate Sense in Banach Spaces
}

\author{
Gurucharan Singh Saluja
}

\begin{abstract}
Suppose $K$ is a nonempty closed convex subset of a real uniformly convex Banach space $E$. Let $S, T: K \rightarrow K$ be two asymptotically quasi-nonexpansive mappings in the intermediate sense such that $F=F(S) \cap F(T)=\{x \in K: S x=T x=x\} \neq \emptyset$. Suppose $\left\{x_{n}\right\}$ is generated iteratively by $x_{1} \in K, x_{n+1}=\left(1-\alpha_{n}\right) T^{n} x_{n}+\alpha_{n} S^{n} y_{n}$, $y_{n}=\left(1-\beta_{n}\right) x_{n}+\beta_{n} T^{n} x_{n}, n \geq 1$, where $\left\{\alpha_{n}\right\}$ and $\left\{\beta_{n}\right\}$ are real sequences in $[a, b]$ for some $a, b \in(0,1)$. If $S$ and $T$ satisfy condition $(B)$ or either $S$ or $T$ is semi-compact, then the sequence $\left\{x_{n}\right\}$ converges strongly to some $q \in F$ and if $E$ satisfying the Opial's condition, then the sequence $\left\{x_{n}\right\}$ converges weakly to some $q \in F$.
\end{abstract}

\section{INTRODUCTION}

Let $K$ be a nonempty subset of a real Banach space $E$. Let $T: K \rightarrow K$ be a mapping, then we denote the set of all fixed points of $T$ by $F(T)$. Let $S, T: K \rightarrow K$ be two given mappings. The set of common fixed points of two mappings $S$ and $T$ will be denoted by $F=F(S) \cap F(T)$. Recall the following concepts.

(1) $T$ is said to be nonexpansive if

$$
\|T x-T y\| \leq\|x-y\|
$$

for all $x, y \in K$.

(2) $T$ is said to be quasi-nonexpansive if $F(T) \neq \emptyset$ and

$$
\|T x-p\| \leq\|x-p\|
$$

2010 Mathematics Subject Classification. 47H09, 47H10, 47J25.

Key words and phrases. Asymptotically quasi-nonexpansive mapping in the intermediate sense, modified Ishikawa type iteration process, common fixed point, strong convergence, uniformly convex Banach space, weak convergence. 
for all $x \in K$ and $p \in F(T)$.

(3) $T$ is said to be asymptotically nonexpansive if there exists a sequence $\left\{a_{n}\right\}$ in $[1, \infty)$ with $a_{n} \rightarrow 1$ as $n \rightarrow \infty$ such that

$$
\left\|T^{n} x-T^{n} y\right\| \leq a_{n}\|x-y\|
$$

for all $x, y \in K$ and $n \geq 1$.

(4) $T$ is said be asymptotically quasi-nonexpansive [7] if $F(T) \neq \emptyset$ and there exists a sequence $\left\{a_{n}\right\}$ in $[1, \infty)$ with $a_{n} \rightarrow 1$ as $n \rightarrow \infty$ such that

$$
\left\|T^{n} x-p\right\| \leq a_{n}\|x-p\|
$$

for all $x \in K, p \in F(T)$ and $n \geq 1$.

(5) $T$ is said to be uniformly $L$-Lipschitzian if there exists a constant $L>0$ such that

$$
\left\|T^{n} x-T^{n} y\right\| \leq L\|x-y\|
$$

for all $x, y \in K$ and $n \geq 1$.

It is clear that every nonexpansive mapping is asymptotically nonexpansive and every asymptotically nonexpansive is uniformly $L$-Lipschitzian with $L=\sup _{n \geq 1}\left\{a_{n}\right\} \geq 1$. Also, if $F(T) \neq \emptyset$, then a nonexpansive mapping is a quasi-nonexpansive mapping and an asymptotically nonexpansive mapping is an asymptotically quasi-nonexpansive mapping but the converse is not true in general.

Recall also that a mapping $T: K \rightarrow K$ is said to be asymptotically quasinonexpansive mapping in the intermediate sense [22] provided that $T$ is uniformly continuous and

$$
\limsup _{n \rightarrow \infty} \sup _{p \in F(T)}\left(\left\|T^{n} x-p\right\|-\|x-p\|\right) \leq 0 .
$$

From the above definitions, it follows that asymptotically nonexpansive mapping must be asymptotically quasi-nonexpansive and asymptotically quasi-nonexpansive mapping in the intermediate sense. But the converse does not hold as the following example:

Example 1.1. Let $X=\mathbb{R}$ be a normed linear space and $K=[0,1]$. For each $x \in K$, we define

$$
T(x)=\left\{\begin{array}{cc}
\lambda x, & \text { if } x \neq 0, \\
0, & \text { if } x=0,
\end{array}\right.
$$

where $0<\lambda<1$. It is obvious that $F(T)=\{0\}$. Now, take $p=0$, then we have

$$
\left|T^{n} x-p\right|=\left|T^{n} x-0\right|=\lambda^{n}|x-0| \leq|x-0|=|x-p|
$$

for all $x \in K, p \in F(T)$ and $n \in \mathbb{N}$. 
Thus $T$ is an asymptotically quasi-nonexpansive mapping with constant sequence $\{1\}$ and

$$
\begin{aligned}
\limsup _{n \rightarrow \infty}\left\{\left|T^{n} x-p\right|-|x-p|\right\} & =\limsup _{n \rightarrow \infty}\left\{\lambda^{n}|x-p|-|x-p|\right\} \\
& \leq 0
\end{aligned}
$$

because $\lim _{n \rightarrow \infty} \lambda^{n}=0$ as $0<\lambda<1$, for all $x \in K, p \in F(T), n \in \mathbb{N}$ and $T$ is continuous. Hence $T$ is an asymptotically quasi-nonexpansive mapping in the intermediate sense.

Example 1.2. Let $X=\mathbb{R}, K=\left[-\frac{1}{\pi}, \frac{1}{\pi}\right]$ and $|\lambda|<1$. For each $x \in K$, define

$$
T(x)=\left\{\begin{array}{cl}
\lambda x \sin (1 / x), & \text { if } x \neq 0, \\
0, & \text { if } x=0 .
\end{array}\right.
$$

Clearly $F(T)=\{0\}$. Since

$$
\begin{gathered}
T x=\lambda x \sin (1 / x) \\
T^{2} x=\lambda^{2} x \sin (1 / x) \sin \left(\frac{1}{\lambda x \sin (1 / x)}\right), \ldots
\end{gathered}
$$

we obtain $\left\{T^{n} x\right\} \rightarrow 0$ uniformly on $K$ as $n \rightarrow \infty$. Thus

$$
\limsup _{n \rightarrow \infty}\left\{\left\|T^{n} x-T^{n} y\right\|-\|x-y\| \vee 0\right\}=0
$$

for all $x, y \in K$. Hence $T$ is an asymptotically nonexpansive mapping in the intermediate sense (ANI in short), but it is not a Lipschitz mapping. In fact, suppose that there exists $\lambda>0$ such that $|T x-T y| \leq \lambda|x-y|$ for all $x, y \in K$. If we take $x=\frac{2}{5 \pi}$ and $y=\frac{2}{3 \pi}$, then

$$
|T x-T y|=\left|\lambda \frac{2}{5 \pi} \sin \left(\frac{5 \pi}{2}\right)-\lambda \frac{2}{3 \pi} \sin \left(\frac{3 \pi}{2}\right)\right|=\frac{2 \lambda}{5 \pi},
$$

whereas

$$
\lambda|x-y|=\lambda\left|\frac{2}{5 \pi}-\frac{2}{3 \pi}\right|=\frac{4 \lambda}{15 \pi},
$$

and hence it is not an asymptotically nonexpansive mapping.

The class of asymptotically nonexpansive mappings which is an important generalization of that nonexpansive mappings was introduced by Goebel and Kirk [3] in 1972. They proved that, if $K$ is a nonempty bounded closed convex subset of a uniformly convex Banach space $E$, then every asymptotically nonexpansive self-mapping of $K$ has a fixed point. Moreover, the set $F(T)$ of fixed points of $T$ is closed and convex.

In 1991, Schu [13] introduced the following Mann-type iterative process:

$$
\left\{\begin{aligned}
x_{1} & =x \in K, \\
x_{n+1} & =\left(1-\alpha_{n}\right) x_{n}+\alpha_{n} T^{n} x_{n}, \quad n \geq 1,
\end{aligned}\right.
$$

where $T: K \rightarrow K$ is an asymptotically nonexpansive mapping with a sequence $\left\{k_{n}\right\}$ such that $\sum_{n=1}^{\infty}\left(k_{n}-1\right)<\infty$ and $\left\{\alpha_{n}\right\}$ is a sequence in $(0,1)$ 
satisfying the condition $\delta \leq \alpha_{n} \leq 1-\delta$ for all $n \geq 1$ for some $\delta>0$. Then the sequence $\left\{x_{n}\right\}$ converges weakly to a fixed point of $T$.

Since 1972, many authors have studied weak and strong convergence problem of the iterative sequences (with errors) for asymptotically nonexpansive mappings (and their generalizations, asymptotically quasi-nonexpansive mappings etc.) in Hilbert spaces and Banach spaces (see,for example, [3, 4, $6,7,8,11,12,13,14,20]$ and references therein).

In 2007, Agarwal et al. [1] introduced the following iteration process:

$$
\left\{\begin{aligned}
x_{1} & =x \in K, \\
x_{n+1} & =\left(1-\alpha_{n}\right) T^{n} x_{n}+\alpha_{n} T^{n} y_{n}, \\
y_{n} & =\left(1-\beta_{n}\right) x_{n}+\beta_{n} T^{n} x_{n}, \quad n \geq 1,
\end{aligned}\right.
$$

where $\left\{\alpha_{n}\right\}$ and $\left\{\beta_{n}\right\}$ are in $(0,1)$. They showed that this process converge at a rate same as that of Picard iteration and faster than Mann for contractions.

The above process deals with one mapping only. The case of two mappings in iterative processes has also remained under study since Das and Debata [2] gave and studied a two mappings process. Later on, many authors, for example Khan and Takahashi [6], Shahzad and Udomene [16] and Takahashi and Tamura [19] have studied the two mappings case of iterative schemes for different types of mappings.

Ishikawa-type iteration process:

$$
\left\{\begin{aligned}
x_{1} & =x \in K, \\
x_{n+1} & =\left(1-\alpha_{n}\right) x_{n}+\alpha_{n} S^{n} y_{n}, \\
y_{n} & =\left(1-\beta_{n}\right) x_{n}+\beta_{n} T^{n} x_{n}, \quad n \geq 1,
\end{aligned}\right.
$$

for two mappings has also been studied by many authors including [2], [6], [18].

Recently, Khan et al. [5] modified the iteration process (2) to the case of two mappings as follows:

$$
\left\{\begin{aligned}
x_{1} & =x \in K, \\
x_{n+1} & =\left(1-\alpha_{n}\right) T^{n} x_{n}+\alpha_{n} S^{n} y_{n}, \\
y_{n} & =\left(1-\beta_{n}\right) x_{n}+\beta_{n} T^{n} x_{n}, \quad n \geq 1,
\end{aligned}\right.
$$

where $\left\{\alpha_{n}\right\}$ and $\left\{\beta_{n}\right\}$ are in $(0,1)$. They established weak and strong convergence theorems in the setting of real Banach spaces.

Remark 1.1. (i) Note that (10) reduces to (8) when $S=T$. Similarly, the process (10) reduces to (7) when $T=I$. 
(ii) The process (8) does not reduce to (7) but (10) does. Thus (10) not only covers the results proved by (8) but also by (7) which are not covered by (8).

(iii) The process (10) is independent of (9) neither of them reduces to the other.

In this paper, we prove some strong convergence theorems for two asymptotically quasi-nonexpansive mappings in the intermediate sense using iteration process (10) in the framework of real uniformly convex Banach spaces. The results presented in this paper extend, improve and generalize some previous work in the existing literature (see, e.g., $[6,7,8,12,13,16]$ and many others).

\section{Preliminaries}

For the sake of convenience, we restate the following concepts.

Let $E$ be a Banach space with its dimension greater than or equal to 2 . The modulus of convexity of $E$ is the function $\delta_{E}(\varepsilon):(0,2] \rightarrow[0,1]$ defined by

$$
\delta_{E}(\varepsilon)=\inf \left\{1-\left\|\frac{1}{2}(x+y)\right\|:\|x\|=1,\|y\|=1, \varepsilon=\|x-y\|\right\} .
$$

A Banach space $E$ is uniformly convex if and only if $\delta_{E}(\varepsilon)>0$ for all $\varepsilon \in(0,2]$.

A mapping $T: K \rightarrow K$ where $K$ is a subset of $E$, is said to satisfy condition $(A)[15]$ if there exists a nondecreasing function $f:[0, \infty) \rightarrow[0, \infty)$ with $f(0)=0, f(r)>0$ for all $r \in(0, \infty)$ such that $\|x-T x\| \geq f(d(x, F(T)))$ for all $x \in K$ where $d(x, F(T))=\inf \left\{\left\|x-x^{*}\right\|: x^{*} \in F(T)\right\}$.

Senter and Dotson [15] approximated fixed points of nonexpansive mapping $T$ by Mann iterates. Later on, Maiti and Ghosh [9] and Tan and Xu [17] studied the approximation of fixed points of a nonexpansive mapping $T$ by Ishikawa iterates under the same condition $(A)$ which is weaker than the requirement that $T$ is demicompact. We modify this condition for two mappings $S$ and $T: K \rightarrow K$ as follows:

Two mappings $S$ and $T: K \rightarrow K$ where $K$ is a subset of a Banach space $E$, are said to satisfy condition $(B)$ if there exists a nondecreasing function $f:[0, \infty) \rightarrow[0, \infty)$ with $f(0)=0, f(r)>0$ for all $r \in(0, \infty)$ such that $a_{1}\|x-S x\|+a_{2}\|x-T x\| \geq f(d(x, F))$ for all $x \in K$, where $d(x, F)=$ $\inf \{\|x-p\|: p \in F=F(S) \cap F(T)\}$ and $a_{1}$ and $a_{2}$ are two nonnegative real numbers such that $a_{1}+a_{2}=1$.

Remark 2.1. Condition $(B)$ reduces to condition $(A)$ when $S=T$.

Definition 2.1. Let $K$ be a nonempty closed subset of a Banach space $E$. A mapping $T: K \rightarrow K$ is said to be semi-compact, if for any bounded sequence 
$\left\{x_{n}\right\}$ in $K$ such that $\lim _{n \rightarrow \infty}\left\|x_{n}-T x_{n}\right\|=0$, there exists a subsequence $\left\{x_{n_{j}}\right\} \subset\left\{x_{n}\right\}$ such that $\lim _{n_{j} \rightarrow \infty} x_{n_{j}}=x \in K$.

A mapping $T: K \rightarrow K$ is said to be demiclosed at zero, if for any sequence $\left\{x_{n}\right\}$ in $K$, the condition $x_{n}$ converges weakly to $x \in K$ and $T x_{n}$ converges strongly to 0 imply $T x=0$.

We say that a Banach space $E$ satisfies the Opial's condition [10] if for each sequence $\left\{x_{n}\right\}$ in $E$ weakly convergent to a point $x$ and for all $y \neq x$

$$
\liminf _{n \rightarrow \infty}\left\|x_{n}-x\right\|<\liminf _{n \rightarrow \infty}\left\|x_{n}-y\right\| .
$$

The examples of Banach spaces which satisfy the Opial's condition are Hilbert spaces and all $L^{p}[0,2 \pi]$ with $1<p \neq 2$ fail to satisfy Opial's condition [10].

Next we state the following useful lemmas to prove our main results.

Lemma 2.1 (See [13]). Let $E$ be a uniformly convex Banach space and $0<\alpha \leq t_{n} \leq \beta<1$ for all $n \in \mathbb{N}$. Suppose further that $\left\{x_{n}\right\}$ and $\left\{y_{n}\right\}$ are sequences of $E$ such that $\limsup _{n \rightarrow \infty}\left\|x_{n}\right\| \leq a$, $\limsup _{n \rightarrow \infty}\left\|y_{n}\right\| \leq a$ and $\lim _{n \rightarrow \infty}\left\|t_{n} x_{n}+\left(1-t_{n}\right) y_{n}\right\|=a$ hold for some $a \geq 0$. Then $\lim _{n \rightarrow \infty} \| x_{n}-$ $y_{n} \|=0$.

Lemma 2.2 (See [17]). Let $\left\{\alpha_{n}\right\}_{n=1}^{\infty},\left\{\beta_{n}\right\}_{n=1}^{\infty}$ and $\left\{r_{n}\right\}_{n=1}^{\infty}$ be sequences of nonnegative numbers satisfying the inequality

$$
\alpha_{n+1} \leq\left(1+\beta_{n}\right) \alpha_{n}+r_{n}, \forall n \geq 1 .
$$

If $\sum_{n=1}^{\infty} \beta_{n}<\infty$ and $\sum_{n=1}^{\infty} r_{n}<\infty$, then $\lim _{n \rightarrow \infty} \alpha_{n}$ exists.

Lemma 2.3 (See [21]). Let $p>1$ and $R>1$ be two fixed numbers and $E$ a Banach space. Then $E$ is uniformly convex if and only if there exists a continuous, strictly increasing and convex function $g:[0, \infty) \rightarrow[0, \infty)$ with $g(0)=0$ such that $\|\lambda x+(1-\lambda) y\|^{p} \leq \lambda\|x\|^{p}+(1-\lambda)\|y\|^{p}-W_{p}(\lambda) g(\|x-y\|)$ for all $x, y \in B_{R}(0)=\{x \in E:\|x\| \leq R\}$, and $\lambda \in[0,1]$, where $W_{p}(\lambda)=$ $\lambda(1-\lambda)^{p}+\lambda^{p}(1-\lambda)$.

\section{Main Results}

In this section, we prove some strong convergence theorems and a weak convergence theorem of the iteration scheme (10) under some suitable hypothesis. In the sequel, we need the following lemma in order to prove our main theorems.

Lemma 3.1. Let $E$ be a real Banach space and $K$ be a nonempty closed convex subset of $E$. Let $S, T: K \rightarrow K$ be two asymptotically quasi-nonexpansive mappings in the intermediate sense such that $F=F(S) \cap F(T) \neq \emptyset$. Let $\left\{x_{n}\right\}$ be the sequence defined by (10). Put

$$
A_{n}=\max \left\{0, \sup _{x \in K, p \in F}\left(\left\|S^{n} x-p\right\|-\|x-p\|\right): \forall n \geq 1\right\}
$$


and

$$
B_{n}=\max \left\{0, \sup _{x \in K, p \in F}\left(\left\|T^{n} x-p\right\|-\|x-p\|\right): \forall n \geq 1\right\}
$$

such that $\sum_{n=1}^{\infty} A_{n}<\infty$ and $\sum_{n=1}^{\infty} B_{n}<\infty$. Then $\lim _{n \rightarrow \infty}\left\|x_{n}-q\right\|$ exists for all $q \in F$.

Proof. Let $q \in F$. Then from (10) and (12), we have

$$
\begin{aligned}
\left\|y_{n}-q\right\| & =\left\|\left(1-\beta_{n}\right) x_{n}+\beta_{n} T^{n} x_{n}-q\right\| \\
& \leq\left(1-\beta_{n}\right)\left\|x_{n}-q\right\|+\beta_{n}\left\|T^{n} x_{n}-q\right\| \\
& \leq\left(1-\beta_{n}\right)\left\|x_{n}-q\right\|+\beta_{n}\left[\left\|x_{n}-q\right\|+B_{n}\right] \\
& \leq\left\|x_{n}-q\right\|+\beta_{n} B_{n} .
\end{aligned}
$$

Again using (10), (11), (12) and (13), we obtain

$$
\begin{aligned}
\left\|x_{n+1}-q\right\|= & \left\|\left(1-\alpha_{n}\right) T^{n} x_{n}+\alpha_{n} S^{n} y_{n}-q\right\| \\
\leq & \left(1-\alpha_{n}\right)\left\|T^{n} x_{n}-q\right\|+\alpha_{n}\left\|S^{n} y_{n}-q\right\| \\
\leq & \left(1-\alpha_{n}\right)\left[\left\|x_{n}-q\right\|+B_{n}\right]+\alpha_{n}\left[\left\|y_{n}-q\right\|+A_{n}\right] \\
= & \left(1-\alpha_{n}\right)\left\|x_{n}-q\right\|+\left(1-\alpha_{n}\right) B_{n}+\alpha_{n}\left\|y_{n}-q\right\| \\
& +\alpha_{n} A_{n} \\
\leq & \left(1-\alpha_{n}\right)\left\|x_{n}-q\right\|+\left(1-\alpha_{n}\right) B_{n}+\alpha_{n}\left[\left\|x_{n}-q\right\|\right. \\
& \left.+\beta_{n} B_{n}\right]+\alpha_{n} A_{n} \\
\leq & \left\|x_{n}-q\right\|+A_{n}+B_{n} \\
= & \left\|x_{n}-q\right\|+d_{n}
\end{aligned}
$$

where $d_{n}=A_{n}+B_{n}$. Since by the hypothesis of the Lemma 3.1, $\sum_{n=1}^{\infty} A_{n}<$ $\infty$ and $\sum_{n=1}^{\infty} B_{n}<\infty$, it follows that $\sum_{n=1}^{\infty} d_{n}<\infty$. Hence from Lemma 2.2 we know that $\lim _{n \rightarrow \infty}\left\|x_{n}-q\right\|$ exists for all $q \in F$. This completes the proof.

Theorem 3.1. Let $E$ be a real uniformly convex Banach space and $K$ be a nonempty closed convex subset of $E$. Let $S, T: K \rightarrow K$ be two uniformly $L$ Lipschitzian asymptotically quasi-nonexpansive mappings in the intermediate sense such that $F=F(S) \cap F(T) \neq \emptyset$. Let $\left\{\alpha_{n}\right\}$ and $\left\{\beta_{n}\right\}$ be sequences in $[a, b]$ for some $a, b \in(0,1)$. From arbitrary $x_{1} \in K$, let $\left\{x_{n}\right\}$ be the sequence defined by (10) and $A_{n}$ and $B_{n}$ be taken as in Lemma 3.1. Then $\lim _{n \rightarrow \infty}\left\|x_{n}-S x_{n}\right\|=\lim _{n \rightarrow \infty}\left\|x_{n}-T x_{n}\right\|=0$.

Proof. By Lemma 3.1, $\lim _{n \rightarrow \infty}\left\|x_{n}-q\right\|$ exists for all $q \in F$. Assume that $\lim _{n \rightarrow \infty}\left\|x_{n}-q\right\|=r$. If $r=0$, the conclusion is obvious. Now suppose $r>0$. We claim $\lim _{n \rightarrow \infty}\left\|x_{n}-S x_{n}\right\|=\lim _{n \rightarrow \infty}\left\|x_{n}-T x_{n}\right\|=0$. Using (10) 
and Lemma 2.3, we have

$$
\begin{aligned}
\left\|y_{n}-q\right\|^{2}= & \left\|\left(1-\beta_{n}\right) T^{n} x_{n}+\beta_{n} x_{n}-q\right\|^{2} \\
\leq & \left(1-\beta_{n}\right)\left\|T^{n} x_{n}-q\right\|^{2}+\beta_{n}\left\|x_{n}-q\right\|^{2} \\
& -W_{2}\left(\beta_{n}\right) g\left(\left\|T^{n} x_{n}-x_{n}\right\|\right) \\
\leq & \left(1-\beta_{n}\right)\left\|T^{n} x_{n}-q\right\|^{2}+\beta_{n}\left\|x_{n}-q\right\|^{2} \\
\leq & \left(1-\beta_{n}\right)\left[\left\|x_{n}-q\right\|+B_{n}\right]^{2}+\beta_{n}\left\|x_{n}-q\right\|^{2} \\
= & \left\|x_{n}-q\right\|^{2}+T_{n}
\end{aligned}
$$

where $T_{n}=\left(1-\beta_{n}\right) B_{n}^{2}+2\left(1-\beta_{n}\right)\left\|x_{n}-q\right\| B_{n}$. Since by assumption $\sum_{n=1}^{\infty} B_{n}<\infty$, it follows that $\sum_{n=1}^{\infty} T_{n}<\infty$. Again using (10), (15) and Lemma 2.3, we have

$$
\begin{aligned}
\left\|x_{n+1}-q\right\|^{2}= & \left\|\left(1-\alpha_{n}\right) T^{n} x_{n}+\alpha_{n} S^{n} y_{n}-q\right\|^{2} \\
\leq & \left(1-\alpha_{n}\right)\left\|T^{n} x_{n}-q\right\|^{2}+\alpha_{n}\left\|S^{n} y_{n}-q\right\|^{2} \\
& -W_{2}\left(\alpha_{n}\right) g\left(\left\|T^{n} x_{n}-S^{n} y_{n}\right\|\right) \\
\leq & \left(1-\alpha_{n}\right)\left[\left\|x_{n}-q\right\|+B_{n}\right]^{2}+\alpha_{n}\left[\left\|y_{n}-q\right\|+A_{n}\right]^{2} \\
& -W_{2}\left(\alpha_{n}\right) g\left(\left\|T^{n} x_{n}-S^{n} y_{n}\right\|\right) \\
\leq & \left(1-\alpha_{n}\right)\left[\left\|x_{n}-q\right\|^{2}+P_{n}\right]+\alpha_{n}\left[\left\|y_{n}-q\right\|^{2}\right. \\
& \left.+Q_{n}\right]-W_{2}\left(\alpha_{n}\right) g\left(\left\|T^{n} x_{n}-S^{n} y_{n}\right\|\right) \\
\leq & \left(1-\alpha_{n}\right)\left[\left\|x_{n}-q\right\|^{2}+P_{n}\right]+\alpha_{n}\left[\left\|x_{n}-q\right\|^{2}\right. \\
& \left.+T_{n}+Q_{n}\right]-W_{2}\left(\alpha_{n}\right) g\left(\left\|T^{n} x_{n}-S^{n} y_{n}\right\|\right) \\
\leq & \left\|x_{n}-q\right\|^{2}+\left(1-\alpha_{n}\right) P_{n}+\alpha_{n}\left[T_{n}+Q_{n}\right] \\
& -W_{2}\left(\alpha_{n}\right) g\left(\left\|T^{n} x_{n}-S^{n} y_{n}\right\|\right) \\
\leq & \left\|x_{n}-q\right\|^{2}+P_{n}+Q_{n}+T_{n} \\
& -W_{2}\left(\alpha_{n}\right) g\left(\left\|T^{n} x_{n}-S^{n} y_{n}\right\|\right) \\
\leq & \left\|x_{n}-q\right\|^{2}+M_{n}-W_{2}\left(\alpha_{n}\right) g\left(\left\|T^{n} x_{n}-S^{n} y_{n}\right\|\right)
\end{aligned}
$$

where $P_{n}=B_{n}^{2}+2\left\|x_{n}-q\right\| B_{n}, Q_{n}=A_{n}^{2}+2\left\|y_{n}-q\right\| A_{n}$ and $M_{n}=P_{n}+$ $Q_{n}+T_{n}$, since by assumption of the theorem $\sum_{n=1}^{\infty} A_{n}<\infty, \sum_{n=1}^{\infty} B_{n}<\infty$ and $\sum_{n=1}^{\infty} T_{n}<\infty$, it follows that $\sum_{n=1}^{\infty} P_{n}<\infty, \sum_{n=1}^{\infty} Q_{n}<\infty$ and $\sum_{n=1}^{\infty} M_{n}<\infty$. Since $W_{2}\left(\alpha_{n}\right) \geq a(1-b)$ and $\sum_{n=1}^{\infty} M_{n}<\infty$. Now (16) 
implies that

$$
a(1-b) \sum_{n=1}^{\infty} g\left(\left\|T^{n} x_{n}-S^{n} y_{n}\right\|\right)<\left\|x_{1}-q\right\|^{2}+\sum_{n=1}^{\infty} M_{n}<\infty .
$$

Since $a(1-b)>0$, therefore, we have $\lim _{n \rightarrow \infty} g\left(\left\|T^{n} x_{n}-S^{n} y_{n}\right\|\right)=0$. Since $g$ is strictly increasing and continuous at 0 , it follows that

$$
\lim _{n \rightarrow \infty}\left\|T^{n} x_{n}-S^{n} y_{n}\right\|=0 \text {. }
$$

Now taking limsup on both the sides of (13), we obtain

$$
\limsup _{n \rightarrow \infty}\left\|y_{n}-q\right\| \leq r .
$$

Since $T$ is asymptotically quasi-nonexpansive mapping in the intermediate sense, we can get that

$$
\left\|T^{n} x_{n}-q\right\| \leq\left\|x_{n}-q\right\|+B_{n} .
$$

for all $n \geq 1$. Taking limsup on both the sides of (20), we obtain

$$
\limsup _{n \rightarrow \infty}\left\|T^{n} x_{n}-q\right\| \leq r \text {. }
$$

Now

$$
\begin{aligned}
\left\|x_{n+1}-q\right\| & =\left\|\left(1-\alpha_{n}\right) T^{n} x_{n}+\alpha_{n} S^{n} y_{n}-q\right\| \\
& =\left\|\left(T^{n} x_{n}-q\right)+\alpha_{n}\left(S^{n} y_{n}-T^{n} x_{n}\right)\right\| \\
& \leq\left\|T^{n} x_{n}-q\right\|+\alpha_{n}\left\|S^{n} y_{n}-T^{n} x_{n}\right\|
\end{aligned}
$$

yields that

$$
r \leq \liminf _{n \rightarrow \infty}\left\|T^{n} x_{n}-q\right\|
$$

So that (21) gives $\lim _{n \rightarrow \infty}\left\|T^{n} x_{n}-q\right\|=r$.

On the other hand, since $S$ is asymptotically quasi-nonexpansive mapping in the intermediate sense, we have

$$
\begin{aligned}
\left\|T^{n} x_{n}-q\right\| & \leq\left\|T^{n} x_{n}-S^{n} y_{n}\right\|+\left\|S^{n} y_{n}-q\right\| \\
& \leq\left\|T^{n} x_{n}-S^{n} y_{n}\right\|+\left\|y_{n}-q\right\|+A_{n} .
\end{aligned}
$$

Thus, we obtain from above inequality

$$
r \leq \liminf _{n \rightarrow \infty}\left\|y_{n}-q\right\| \text {. }
$$

By using (19) and (23), we obtain

$$
\lim _{n \rightarrow \infty}\left\|y_{n}-q\right\|=r .
$$

Thus $r=\lim _{n \rightarrow \infty}\left\|y_{n}-q\right\|=\lim _{n \rightarrow \infty}\left\|\left(1-\beta_{n}\right)\left(x_{n}-q\right)+\beta_{n}\left(T^{n} x_{n}-q\right)\right\|$ gives by Lemma 2.1 that

$$
\lim _{n \rightarrow \infty}\left\|T^{n} x_{n}-x_{n}\right\|=0 .
$$


Now

$$
\left\|y_{n}-x_{n}\right\|=\beta_{n}\left\|T^{n} x_{n}-x_{n}\right\| .
$$

Hence by (25), we obtain

$$
\lim _{n \rightarrow \infty}\left\|y_{n}-x_{n}\right\|=0
$$

Also note that

$$
\begin{aligned}
\left\|x_{n+1}-x_{n}\right\| & =\left\|\left(1-\alpha_{n}\right) T^{n} x_{n}+\alpha_{n} S^{n} y_{n}-x_{n}\right\| \\
& \leq\left\|T^{n} x_{n}-x_{n}\right\|+\alpha_{n}\left\|T^{n} x_{n}-S^{n} y_{n}\right\| \rightarrow 0 \quad \text { as } n \rightarrow \infty
\end{aligned}
$$

so that

$$
\left\|x_{n+1}-y_{n}\right\| \leq\left\|x_{n+1}-x_{n}\right\|+\left\|y_{n}-x_{n}\right\| \rightarrow 0 \quad \text { as } n \rightarrow \infty
$$

Furthermore, from

$$
\left\|x_{n+1}-S^{n} y_{n}\right\| \leq\left\|x_{n+1}-x_{n}\right\|+\left\|x_{n}-T^{n} x_{n}\right\|+\left\|T^{n} x_{n}-S^{n} y_{n}\right\|
$$

using (18), (25) and (27), we find that

$$
\lim _{n \rightarrow \infty}\left\|x_{n+1}-S^{n} y_{n}\right\|=0 .
$$

Again note that

$$
\begin{aligned}
\left\|x_{n+1}-T x_{n+1}\right\| \leq & \left\|x_{n+1}-T^{n+1} x_{n+1}\right\|+\left\|T^{n+1} x_{n+1}-T^{n+1} x_{n}\right\| \\
& +\left\|T^{n+1} x_{n}-T x_{n+1}\right\| \\
\leq & \left\|x_{n+1}-T^{n+1} x_{n+1}\right\|+L\left\|x_{n+1}-x_{n}\right\| \\
& +L\left\|T^{n} x_{n}-x_{n+1}\right\| \\
= & \left\|x_{n+1}-T^{n+1} x_{n+1}\right\|+L\left\|x_{n+1}-x_{n}\right\| \\
& +L \alpha_{n}\left\|T^{n} x_{n}-S^{n} y_{n}\right\|
\end{aligned}
$$

yields

$$
\lim _{n \rightarrow \infty}\left\|x_{n}-T x_{n}\right\|=0
$$

Now

$$
\begin{aligned}
\left\|x_{n}-S^{n} x_{n}\right\| \leq & \left\|x_{n}-x_{n+1}\right\|+\left\|x_{n+1}-S^{n} y_{n}\right\| \\
& +\left\|S^{n} y_{n}-S^{n} x_{n}\right\| \\
\leq & \left\|x_{n}-x_{n+1}\right\|+\left\|x_{n+1}-S^{n} y_{n}\right\| \\
& +L\left\|y_{n}-x_{n}\right\| \rightarrow 0 \quad \text { as } n \rightarrow \infty
\end{aligned}
$$


Thus

$$
\begin{aligned}
\left\|x_{n+1}-S x_{n+1}\right\| \leq & \left\|x_{n+1}-S^{n+1} x_{n+1}\right\|+\left\|S^{n+1} x_{n+1}-S x_{n+1}\right\| \\
\leq & \left\|x_{n+1}-S^{n+1} x_{n+1}\right\|+L\left\|S^{n} x_{n+1}-x_{n+1}\right\| \\
\leq & \left\|x_{n+1}-S^{n+1} x_{n+1}\right\|+L\left(\left\|S^{n} x_{n+1}-S^{n} y_{n}\right\|\right. \\
& \left.+\left\|S^{n} y_{n}-x_{n+1}\right\|\right) \\
\leq & \left\|x_{n+1}-S^{n+1} x_{n+1}\right\|+L^{2}\left\|x_{n+1}-y_{n}\right\| \\
& +L\left\|S^{n} y_{n}-x_{n+1}\right\|
\end{aligned}
$$

implies

$$
\lim _{n \rightarrow \infty}\left\|x_{n}-S x_{n}\right\|=0 .
$$

This completes the proof.

Theorem 3.2. Let $E$ be a real Banach space and $K$ be a nonempty closed convex subset of $E$. Let $S, T: K \rightarrow K$ be two asymptotically quasi-nonexpansive mappings in the intermediate sense such that $F=F(S) \cap F(T) \neq \emptyset$. Let $\left\{x_{n}\right\}$ be the sequence defined by (10) and $A_{n}$ and $B_{n}$ be taken as in Lemma 3.1. Then $\left\{x_{n}\right\}$ converges strongly to a common fixed point of the mappings $S$ and $T$ if and only if $\liminf _{n \rightarrow \infty} d\left(x_{n}, F\right)=0$, where $d(x, F)=\inf \{\|x-p\|$ : $p \in F\}$.

Proof. Necessity is obvious. Conversely, suppose that $\liminf _{n \rightarrow \infty} d\left(x_{n}, F\right)=$ 0. As proved in Lemma 3.1, $\lim _{n \rightarrow \infty}\left\|x_{n}-w\right\|$ exists for all $w \in F$, therefore $\lim _{n \rightarrow \infty} d\left(x_{n}, F\right)$ exists. But by hypothesis, $\liminf _{n \rightarrow \infty} d\left(x_{n}, F\right)=0$, therefore we have $\lim _{n \rightarrow \infty} d\left(x_{n}, F\right)=0$. Next, we show that $\left\{x_{n}\right\}$ is a Cauchy sequence in $K$. By (14) and $p \in F$, we have

$$
\begin{aligned}
\left\|x_{n+m}-p\right\| & \leq\left\|x_{n+m-1}-p\right\|+d_{n+m-1} \\
& \leq \cdots \\
& \leq \cdots \\
& \leq\left\|x_{n}-p\right\|+\sum_{k=n}^{n+m-1} d_{k} .
\end{aligned}
$$

Let $\varepsilon>0$ be arbitrary chosen. Since $\lim _{n \rightarrow \infty} d\left(x_{n}, F\right)=0$, there exists a positive integer $n_{0}$ such that $d\left(x_{n}, F\right)<\frac{\varepsilon}{8}$ and $\sum_{k=n}^{n+m-1} d_{k}<\frac{\varepsilon}{2}$ for all $n \geq n_{0}$. In particular, inf $\left\{\left\|x_{n_{0}}-p\right\|: p \in F\right\}<\frac{\varepsilon}{8}$. Thus there must exists $w \in F$ such that $\left\|x_{n_{0}}-w\right\|<\frac{\varepsilon}{4}$. 
Now, for all $m, n \geq n_{0}$ and from (31), we have

$$
\begin{aligned}
\left\|x_{n+m}-x_{n}\right\| & \leq\left\|x_{n+m}-w\right\|+\left\|x_{n}-w\right\| \\
& \leq\left\|x_{n}-w\right\|+\sum_{k=n}^{n+m-1} d_{k}+\left\|x_{n}-w\right\| \\
& \leq\left\|x_{n_{0}}-w\right\|+\sum_{k=n_{0}}^{n+m-1} d_{k}+\left\|x_{n_{0}}-w\right\| \\
& =2\left\|x_{n_{0}}-w\right\|+\sum_{k=n_{0}}^{n+m-1} d_{k} \\
& <2\left(\frac{\varepsilon}{4}\right)+\frac{\varepsilon}{2}=\varepsilon .
\end{aligned}
$$

Hence $\left\{x_{n}\right\}$ is a Cauchy sequence in a closed subset $K$ of a Banach space $E$ and so it must converges to a point $z$ in $K$. Now, $\lim _{n \rightarrow \infty} d\left(x_{n}, F\right)$ gives that $d(z, F)=0$. Since $F$ is closed, so we have $z \in F$. This shows that $\left\{x_{n}\right\}$ converges strongly to a common fixed point of the mappings $S$ and $T$. This completes the proof.

Theorem 3.3. Let $E$ be a real uniformly convex Banach space and $K$ be a nonempty closed convex subset of $E$. Let $S, T: K \rightarrow K$ be two uniformly $L$ Lipschitzian asymptotically quasi-nonexpansive mappings in the intermediate sense such that $F=F(S) \cap F(T) \neq \emptyset$. Let $\left\{\alpha_{n}\right\}$ and $\left\{\beta_{n}\right\}$ be sequences in $[a, b]$ for some $a, b \in(0,1)$. From arbitrary $x_{1} \in K$, let $\left\{x_{n}\right\}$ be the sequence defined by (10) and $A_{n}$ and $B_{n}$ be taken as in Lemma 3.1. Suppose one of the mappings in $S$ and $T$ is semi-compact. Then $\left\{x_{n}\right\}$ converges strongly to a common fixed point of the mappings $S$ and $T$.

Proof. Suppose $S$ is semi-compact. By Theorem 3.1, we have

$$
\lim _{n \rightarrow \infty}\left\|x_{n}-S x_{n}\right\|=0 .
$$

So there exists a subsequence $\left\{x_{n_{j}}\right\}$ of $\left\{x_{n}\right\}$ such that $\lim _{n_{j} \rightarrow \infty} x_{n_{j}}=p \in$ $K$. Now Theorem 3.1 guarantees that $\lim _{n_{j} \rightarrow \infty}\left\|x_{n_{j}}-S x_{n_{j}}\right\|=0$ and $\lim _{n_{j} \rightarrow \infty}\left\|x_{n_{j}}-T x_{n_{j}}\right\|$ $=0$ and so $\|p-S p\|=0$ and $\|p-T p\|=0$. This implies that $p \in F=$ $F(S) \cap F(T)$. Since $\lim _{n \rightarrow \infty} d\left(x_{n}, F\right)=0$, it follows, as in the proof of Theorem 3.2, that $\left\{x_{n}\right\}$ converges strongly to a common fixed point of the mappings $S$ and $T$. This completes the proof.

Applying Theorem 3.2, we obtain strong convergence of the process (10) under the condition $(B)$ as follows. 
Theorem 3.4. Let $E$ be a real uniformly convex Banach space and $K$ be a nonempty closed convex subset of $E$. Let $S, T: K \rightarrow K$ be two uniformly $L$ Lipschitzian asymptotically quasi-nonexpansive mappings in the intermediate sense such that $F=F(S) \cap F(T) \neq \emptyset$. Let $\left\{\alpha_{n}\right\}$ and $\left\{\beta_{n}\right\}$ be sequences in $[a, b]$ for some $a, b \in(0,1)$. From arbitrary $x_{1} \in K$, let $\left\{x_{n}\right\}$ be the sequence defined by (10) and $A_{n}$ and $B_{n}$ be taken as in Lemma 3.1. If $S$ and $T$ satisfy condition $(B)$, then $\left\{x_{n}\right\}$ converges strongly to a common fixed point of the mappings $S$ and $T$.

Proof. We proved in Theorem 3.1 that

$$
\lim _{n \rightarrow \infty}\left\|x_{n}-S x_{n}\right\|=\lim _{n \rightarrow \infty}\left\|x_{n}-T x_{n}\right\|=0 .
$$

From the condition $(B)$ and (32), we have

$$
\lim _{n \rightarrow \infty} f\left(d\left(x_{n}, F\right)\right)=0 .
$$

Since $f:[0, \infty) \rightarrow[0, \infty)$ is a nondecreasing function satisfying $f(0)=0$, $f(r)>0$ for all $r \in(0, \infty)$, therefore we have

$$
\lim _{n \rightarrow \infty} d\left(x_{n}, F\right)=0 .
$$

Hence, Theorem 3.2 implies that $\left\{x_{n}\right\}$ converges strongly to a point in $F$. This completes the proof.

Theorem 3.5. Let $E$ be a real uniformly convex Banach space satisfying Opial's condition and $K$ be a nonempty closed convex subset of $E$. Let $S, T: K \rightarrow K$ be two uniformly L-Lipschitzian asymptotically quasinonexpansive mappings in the intermediate sense such that $F=F(S) \cap$ $F(T) \neq \emptyset$. Let $\left\{\alpha_{n}\right\}$ and $\left\{\beta_{n}\right\}$ be sequences in $[a, b]$ for some $a, b \in(0,1)$. From arbitrary $x_{1} \in K$, let $\left\{x_{n}\right\}$ be the sequence defined by (10) and $A_{n}$ and $B_{n}$ be taken as in Lemma 3.1. Suppose that $I-S$ and $I-T$ are demiclosed at zero. Then $\left\{x_{n}\right\}$ converges weakly to a common fixed point of $S$ and $T$.

Proof. Let $p$ be a common fixed point of $S$ and $T$. Then $\lim _{n \rightarrow \infty}\left\|x_{n}-p\right\|$ exists as proved in Lemma 3.1. We prove that $\left\{x_{n}\right\}$ has a unique weak subsequential limit in $F=F(S) \cap F(T)$. For, let $u$ and $v$ be weak limits of the subsequences $\left\{x_{n_{i}}\right\}$ and $\left\{x_{n_{j}}\right\}$ of $\left\{x_{n}\right\}$, respectively. By Theorem 3.1, $\lim _{n \rightarrow \infty}\left\|x_{n}-S x_{n}\right\|=0$ and $I-S$ is demiclosed at zero by the assumption of the theorem, therefore we obtain $S u=u$. Similarly, $T u=u$. Thus $u \in$ $F(S) \cap F(T)$. Again in the same fashion, we can prove that $v \in F(S) \cap F(T)$. Next, we prove the uniqueness. To this end, if $u$ and $v$ are distinct then by 
Opial's condition,

$$
\begin{aligned}
\lim _{n \rightarrow \infty}\left\|x_{n}-u\right\| & =\lim _{n_{i} \rightarrow \infty}\left\|x_{n_{i}}-u\right\| \\
& <\lim _{n_{i} \rightarrow \infty}\left\|x_{n_{i}}-v\right\| \\
& =\lim _{n \rightarrow \infty}\left\|x_{n}-v\right\| \\
& =\lim _{n_{j} \rightarrow \infty}\left\|x_{n_{j}}-v\right\| \\
& <\lim _{n_{j} \rightarrow \infty}\left\|x_{n_{j}}-u\right\| \\
& =\lim _{n \rightarrow \infty}\left\|x_{n}-u\right\| .
\end{aligned}
$$

This is a contradiction. Hence $u=v \in F$. Thus $\left\{x_{n}\right\}$ converges weakly to a common fixed point of $S$ and $T$. This completes the proof.

Remark 3.1. Our results extend and improve several known results from the previous work given in the existing literature.

\section{Conclusion}

In this paper we establish some strong convergence theorems and a weak convergence theorem of the iteration scheme (10) for two asymptotically quasi-nonexpansive mappings in the intermediate sense which is more general than the class of nonexpansive, quasi-nonexpansive asymptotically nonexpansive and asymptotically quasi-nonexpansive mappings and the iteration scheme is independent of Ishikawa type iteration scheme (9). Thus our results are good improvement and extension of some corresponding previous results from the existing literature (see, e.g., $[6,7,8,12,13,16]$ and many others).

Acknowledgements. The author would like to thanks the anonymous referee for his careful reading and valuable suggestions on the manuscript.

\section{REFERENCES}

[1] R.P. Agarwal, D. O'Regan, D.R. Sahu, Iterative construction of fixed points of nearly asymptotically nonexpansive mappings, J. Nonlinear Convex Anal. 8(1) (2007), 6179.

[2] G. Das, J.P. Debate, Fixed points of quasi-nonexpansive mappings, Indian J. Pure Appl. Math. 17(11)(1986), 1263-1269.

[3] K. Goebel, W.A. Kirk, A fixed point theorem for asymptotically nonexpansive mappings, Proc. Amer. Math. Soc. 35(1)(1972), 171-174.

[4] S.H. Khan, H. Fukhar-ud-din, Weak and strong convergence of a scheme with errors for two nonexpansive mappings, Nonlinear Anal. 61(8)(2005), 1295-1301.

[5] S.H. Khan, Y.J. Cho, M. Abbas, Convergence to common fixed points by a modified iteration process, J. Appl. Math. Comput. doi:10.1007/s12190-010-0381-z. 
[6] S.H. Khan, W. Takahashi, Approximating common fixed points of two asymptotically nonexpansive mappings, Sci. Math. Jpn. 53(1)(2001), 143-148.

[7] Q.H. Liu, Iterative sequences for asymptotically quasi-nonexpansive mappings, J. Math. Anal. Appl. 259(2001), 1-7.

[8] Q.H. Liu, Iterative sequences for asymptotically quasi-nonexpansive mappings with error member, J. Math. Anal. Appl. 259(2001), 18-24.

[9] M. Maiti, M.K. Ghosh, Approximating fixed points by Ishikawa iterates, Bull. Austral. Math. Soc. 40(1)(1989), 113-117.

[10] Z. Opial, Weak convergence of the sequence of successive approximations for nonexpansive mappings, Bull. Amer. Math. Soc. 73(1967), 591-597.

[11] M.O. Osilike, S.C. Aniagbosor, Weak and strong convergence theorems for fixed points of asymptotically nonexpansive mappings, Math. and Computer Modelling 32(2000), 1181-1191.

[12] B.E. Rhoades, Fixed point iteration for certain nonlinear mappings, J. Math. Anal. Appl. 183(1994), 118-120.

[13] J. Schu, Weak and strong convergence to fixed points of asymptotically nonexpansive mappings, Bull. Austral. Math. Soc. 43(1)(1991), 153-159.

[14] J. Schu, Iterative construction of fixed points of asymptotically nonexpansive mappings, J. Math. Anal. Appl. 158(1991), 407-413.

[15] H.F. Senter, W.G. Dotson, Approximating fixed points of nonexpansive mappings, Proc. Amer. Math. Soc. 44(1974), 375-380.

[16] N. Shahzad, A. Udomene, Approximating common fixed points of two asymptotically quasi nonexpansive mappings in Banach spaces, Fixed point Theory and Appl. 2006(2006), Article ID 18909, Pages 1-10.

[17] K.K. Tan, H.K. Xu, Approximating fixed points of nonexpansive mappings by the Ishikawa iteration process, J. Math. Anal. Appl. 178(1993), 301-308.

[18] W. Takahashi, T. Tamura, Limit theorems of operators by convex combinations of nonexpansive retractions in Banach spaces, J. Approx. Theory 91(3)(1997), 386-397.

[19] W. Takahashi, T. Tamura, Convergence theorems for a pair of nonexpansive mappings, J. Convex Anal. 5(1)(1998), 45-56.

[20] B.L. Xu, M.A. Noor, Fixed point iterations for asymptotically nonexpansive mappings in Banach spaces, J. Math. Anal. Appl. 267(2)(2002), 444-453.

[21] H.K. Xu, Existence and convergence for fixed points of mappings of asymptotically nonexpansive type, Nonlinear Analysis, 16(1991), 1139-1146.

[22] Y. Yao, Y.C. Liou, New iterative schemes for asymptotically quasi-nonexpansive mappings, Journal of Inequalities and Applications, Volume 2010, Article ID 934692, 9 pages, doi:10.1155/2010/934692. 
Gurucharan Singh Saluja

Department of Mathematics

Govt. Nagarjuna P.G. College of Science RAIPUR-492010 (C.G.)

INDIA

E-mail address: saluja1963@gmail.com 